\title{
O mercado de Debêntures e o Financiamento Produtivo no Brasil: uma Análise de Cointegração e Causalidade
}

\section{The Market of Corporate Debentures and the Financing of Produc- tive Sector in Brazil: a Cointegration and Causality Analysis}

\author{
Renê Coppe Pimentel ${ }^{a}$; Edna Ferreira Peres ${ }^{b}$; Gerlando Augusto Sampaio Franco de Lima ${ }^{c}$ \\ a Professor da FIPECAFI - Fundação Instituto de Pesq. Contábeis, Atuariais e Financeiras, \\ Doutorado em Controladoria e Contabilidade pela Universidade de São Paulo, USP, São Paulo, SP - Brasil - E-mail: rene.pimentel@fipecafi.org \\ ${ }^{b}$ Analista do Centro de Estudos de Mercado de Capitais - CEMEC., \\ Graduação em andamento em Ciências Atuariais pela Universidade de São Paulo USP. São Paulo, SP - Brasil - E-mail: edna.peres@usp.br \\ Professor da Faculdade de Economia, Administração e Contabilidade, FEA-USP, \\ Pós-Doutorado pela Universidade de Coimbra - Faculdade de Economia, Doutorado em Controladoria e Contabilidade pela \\ Faculdade de Economia, Administração e Contabilidade - USP, São Paulo, SP - Brasil -E-mail: gerlando@usp.br
}

\section{Resumo}

Este artigo analisa a evolução do mercado brasileiro de debêntures e seu papel no financiamento empresarial entre 1995 e 2009 . Além da descrição do mercado de debêntures, o artigo estuda, por meio de análise de cointegração e causalidade, a relação temporal entre o mercado de debêntures e o crescimento econômico brasileiro. Adicionalmente, compara-se o mercado de debêntures vis-à-vis o mercado de crédito bancário como instrumentos complementares e concorrentes no financiamento produtivo brasileiro. Os testes sugerem que existe cointegração significativa entre as variáveis em estudo e que, de maneira geral, o mercado de debêntures é causa-Granger do crescimento econômico, ou seja, existe evidência significativa de que o aumento no volume de debêntures impulsiona o crescimento econômico. Também se verificou que o mercado de debêntures parece ser mais relevante do que o mercado de crédito bancário para influenciar o crescimento econômico.

Palavras-chave: Mercado de capitais; Desenvolvimento econômico; Debêntures; Análise de séries temporais.

\begin{abstract}
This paper analyzes the evolution of the Brazilian corporate debt market and its role on corporate financing from 1994 to 2009. Besides the description of the corporate debt market, the paper analyzes, by using co-integration and causality analysis, if there is long-term relationship between corporate debt market and Brazilian economic growth and the direction of the relationship. Additionally, the corporate debt market is compared to the banking market as complementary and competitive instrument of Brazilian productive financing. Tests suggest that there is significant co-integration between the variables under analysis and, in general, the corporate debt market is Granger-cause of economic growth, which means that there is signifcant influence of debt volume growth on stimulating economic growth. It was also verified that the corporate debt market seems to be more relevant than the banking market in influencing economic growth.
\end{abstract}

Keywords: Capital market; Economic development; Corporate debt market and Time-series Analysis. 


\section{INTRODUÇÃO}

O mercado financeiro assume considerável relevância na mobilização e alocação eficiente de recursos, visto que é capaz de reunir agentes poupadores e investidores de forma a otimizar a utilização das fontes financeiras, melhorando as condições de liquidez e gerando alternativas para administração de riscos econômicos. Nesse contexto, sistemas financeiros eficientes geram impactos positivos à economia em termos de produtividade, acumulação de capital, aumento de poupanças e crescimento econômico.

De forma mais específica, o mercado de capitais busca aproximar agentes poupadores dos agentes tomadores, de modo que as instituições financeiras não atuem, em regra, como parte direta na operação, mas como interveniente. Assim, fundamentado na plataforma teórica, iniciada por Schumpeter (1934), sobre a relação entre desenvolvimento econômico e mercado financeiro, este artigo analisa a evolução do mercado brasileiro de debêntures e sua relação com o financiamento empresarial entre 1994 e 2009.

Desta forma, o presente estudo tem como objetivo (1) descrever o mercado de debêntures e seu papel no financiamento do setor produtivo brasileiro, (2) analisar a relação temporal entre o mercado de debêntures e o crescimento econômico brasileiro a partir do plano real e (3) comparar a relação temporal entre mercado de debêntures e crescimento econômico com a relação temporal das operações de crédito bancário como instrumento complementar e concorrente no financiamento produtivo brasileiro.

O estudo se justifica por trazer à discussão um antigo desafio de como financiar a atividade produtiva no Brasil, visto que as empresas disputam recursos da poupança nacional com o Governo Federal (que oferece uma das maiores taxas reais de juros do mundo) e não encontram no sistema bancário tradicional alternativas viáveis de financiamento de capital em termos de prazos e taxas de juros. Assim, verificar a efetividade do mercado de dívidas no financiamento econômico é fundamental para traçar diretrizes que visem o fortalecimento do sistema econômico e competitividade da indústria brasileira, reduzindo a dependência do crédito bancário, alongando prazos, oferecendo maiores volumes e funcionando como uma oportunidade adequada de funding para as empresas.

O restante do artigo está dividido como segue: o Tópico 2 revisa a literatura e apresenta um breve retrospecto da economia brasileira e do mercado de capitais; o Tópico 3 descreve o mercado de debêntures após o plano real; o Tópico 4 apresenta a metodologia e descreve as variáveis; o Tópico 5 apresenta e analisa os resultados dos testes estatísticos; e, finalmente, o Tópico 6 apresenta as considerações finais e perspectivas de pesquisas futuras.

\section{A ECONOMIA E O MERCADO DE CAPITAIS}

Diversos estudos verificaram a existência de relação significativa entre o crescimento econômico e o desenvolvimento do sistema financeiro e do mercado de capitais baseados na plataforma teórica proposta por Schumpeter (1934). De acordo com Witt (2002) o grande diferencial da plataforma teórica de Schumpeter foi buscar na teoria Darwiniana (Teoria da Evolução) a idéia evolução contínua das nações de forma a abandonar o método estático que predominava na época em detrimento de uma abordagem de equilíbrio temporalmente dinâmico em uma nação. 
Um dos principais estudos foi desenvolvido por King e Levine (1993), que verificaram, por meio de estudo cross-country, que diversas medidas de desenvolvimento financeiro estavam fortemente associadas ao crescimento econômico de uma gama de países ( 80 no total) durante as décadas de 60,70 e 80 .

No Brasil, as empresas possuem, tradicionalmente, um alto índice de financiamento através de empréstimos bancários. Segundo Nascimento (2004, p. 130), “o sistema bancário nacional responde por mais de $90 \%$ do crédito privado e é extremamente concentrado no curto prazo". Esse panorama teve início desde a formação e expansão do parque industrial brasileiro ocorrida na década de 50, em que observaram-se profundas alterações no perfil industrial em virtude dos maciços investimentos na infraestrutura e nas indústrias de transformação. Essas mudanças implicaram a imobilização de recursos financeiros por períodos mais longos em vista de sua aplicação em setores onde a intensidade de capital e os prazos de maturação são maiores.

Durante a década de 60, ante a falta de canais eficientes de obtenção de financiamentos externos de médio e longo prazos, o Governo foi levado a utilizar técnicas de financiamento interno - autofinanciamento com emissão descontrolada de moeda gerando altos índices de inflação e aumento de tributação, fazendo com que a parcela do PIB - Produto Interno Bruto recolhido pelo Governo crescesse de 14,9\% em 1949 para 20\% em 1959 (ANDREZO e LIMA, 2007).

Com a alta inflação e instabilidade econômica, houve desestímulo à formação de poupança, inibição dos investidores e, consequentemente, dificuldade de captação de recursos a médio e longo prazos. De acordo com Andrezo e Lima (2007), "a escassez de recursos de médio e longo prazos levou as empresas a se financiarem com recursos de curto prazo, o que limitava o crescimento."

Além das questões conjunturais que inibiam os investimentos de longo prazo, não existia uma estrutura legal com finalidade de regular as atividades desenvolvidas no mercado de capitais, até que, em 1964, foram tomadas diversas medidas para organizar e dar consistência ao mercado nacional, dentre as quais: a constituição de um banco central unificado; criação da Lei da Reforma do Sistema Financeiro Nacional (Lei No 4.595/64); Lei do Mercado de Capitais (Lei $n^{\circ}$ 4.728/65); Lei de Capitais Estrangeiros (Lei $n^{\circ} 4.131 / 62$ ); Lei de Correção Monetária (Lei ${ }^{\circ} 4.357 / 64$ ), bem como a regulamentação de bancos de investimentos, bolsas e sociedades corretoras e distribuidoras de títulos e valores mobiliários.

A ampla reforma se estendeu pelos anos 70, com a criação da Comissão de Valores Mobiliários (CVM) e a reestruturação da Lei das Sociedades por Ações (Lei n ${ }^{\circ}$ 6.404/76), assegurando, assim, direitos mínimos aos investidores..

Outras medidas foram tomadas para fortalecer o mercado de capitais brasileiro e facilitar o financiamento de empresas, abrindo, assim, outras possibilidades de obtenção de capital que não os empréstimos bancários, incentivando a criação voluntária de poupança e estimulando a captação de recursos por meio de emissão de ações e títulos de dívida. O mercado de debêntures durante o período de incertezas econômicas e políticas foi analisado em maior detalhe por Anderson (1999).

Em 1994, com o Plano Real, houve estabilização dos indicadores inflacionários em níveis substancialmente mais baixos que os apresentados antes da criação do plano. Isso incentivou enormemente a formação de uma poupança financeira de médio e longo prazo no Brasil. Adicionalmente, observou-se a abertura da economia brasileira ao mercado internacional de forma muito mais acentuada do que nos anos anteriores, propiciando um fluxo de capitais 
estrangeiros nunca visto anteriormente.

Outro fator de impulso ao mercado de capitais foi o expressivo avanço no fluxo de informações, proporcionados pela evolução nos meios de comunicação e transmissão de dados.

A evolução do mercado de capitais brasileiro, assim outros países emergentes analisados por Akimov e Dollery (2010), foi caracterizada por mudanças no sistema financeiro que ocorreram, principalmente, como resultado de problemas econômicos e políticos já existentes causados (causadores) pela ineficiência na alocação de recursos. Assim, normalmente são tomadas medidas meramente paliativas ao invés de reformas preventivas visando possíveis problemas de alocação de recurso e fortalecimento econômico de longo prazo.

\section{O mercado de debêntures após o Plano Real}

Desde o início do plano real, o mercado primário de debêntures tem representado a maior fonte de captações no mercado de capitais, condição ilustrada no Gráfico 1. As captações primárias por meio de debêntures são significativamente maiores que o mercado de ações e de notas promissórias. Essa tendência foi muito mais evidente nos anos de 2005 e 2006 - mesmo que grandes volumes captados sejam referentes às empresas de leasing, não é possível tirar o mérito desse instrumento no financiamento empresarial direto.

Além de seu papel no financiamento do setor produtivo, as emissões de debêntures são importante instrumento de quebra de assimetria informacional entre investidores e gestores de empresas. Conforme Sanvicente (2001), as operações de colocação de debêntures têm impacto significativo sobre a riqueza dos investidores em ações de empresas que registram emissões de debêntures, pois investidores do mercado de ações reagem à informação de registro de emissão como se recebessem sinais sobre as perspectivas futuras de lucro das empresas emissoras.

Gráfico 1 - Evolução do mercado primário de ações, debêntures e notas promissórias no período de 1995 a 2009 (em milhões de Reais).

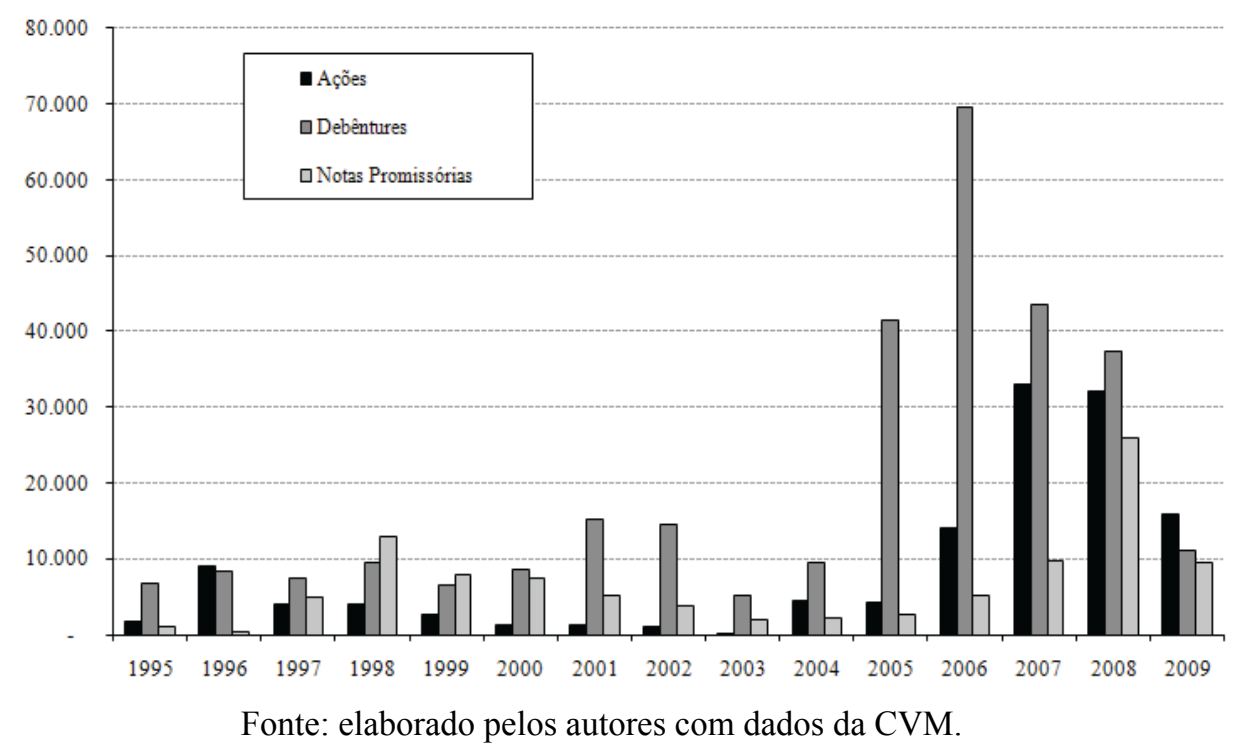

As captações ocorridas no mercado primário fizeram com que houvesse um significativo aumento do saldo total de debêntures emitidas, e o crescimento do saldo da carteira ocorreu de forma mais acelerada que o produto interno bruto (PIB) brasileiro. Esse fato é verificado quando 
se analisa a evolução do estoque de debêntures em relação ao PIB, conforme apresentado no Gráfico 2.

Gráfico 2 - Evolução do estoque de debêntures em valores nominais e percentual do PIB

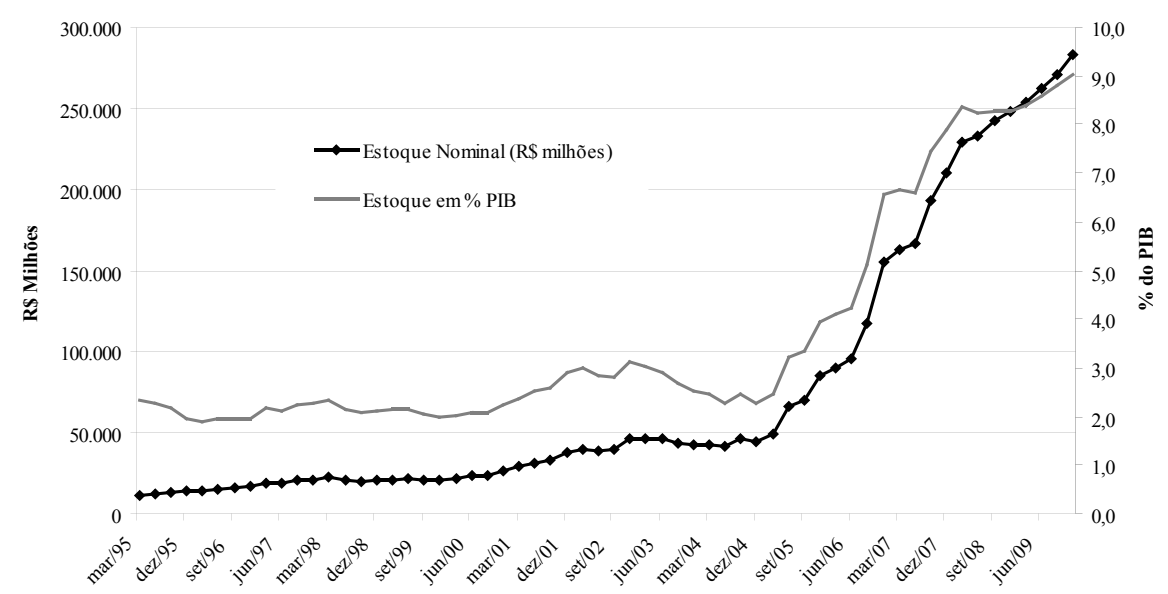

Fonte: elaborado pelos autores com dados do CETIP e BACEN.

O estoque de debêntures, até 2005, representava menos de 3\% do PIB e chegou ao patamar de $9 \%$ do PIB em 2009. Essa grande evolução foi impulsionada justamente pelo grande volume de captações ocorridas a partir de 2005 por empresas de leasing. Não obstante, é importante destacar que não houve grandes aumentos nos números de novas emissões, pelo contrário, o número médio entre 1995 e 2000 é maior do que o apresentado entre 2001 e 2009. Porém, o volume médio captado por emissão, na década de 90, é muito pequeno quando comparado ao de 2008. Em 2008, o volume médio de cada emissão chegou a ser maior que R $\$ 2,5$ bilhões, conforme pode ser observado no Gráfico 3.

Gráfico 3 - Evolução número de emissões por trimestre e volume médio de captação por emissão

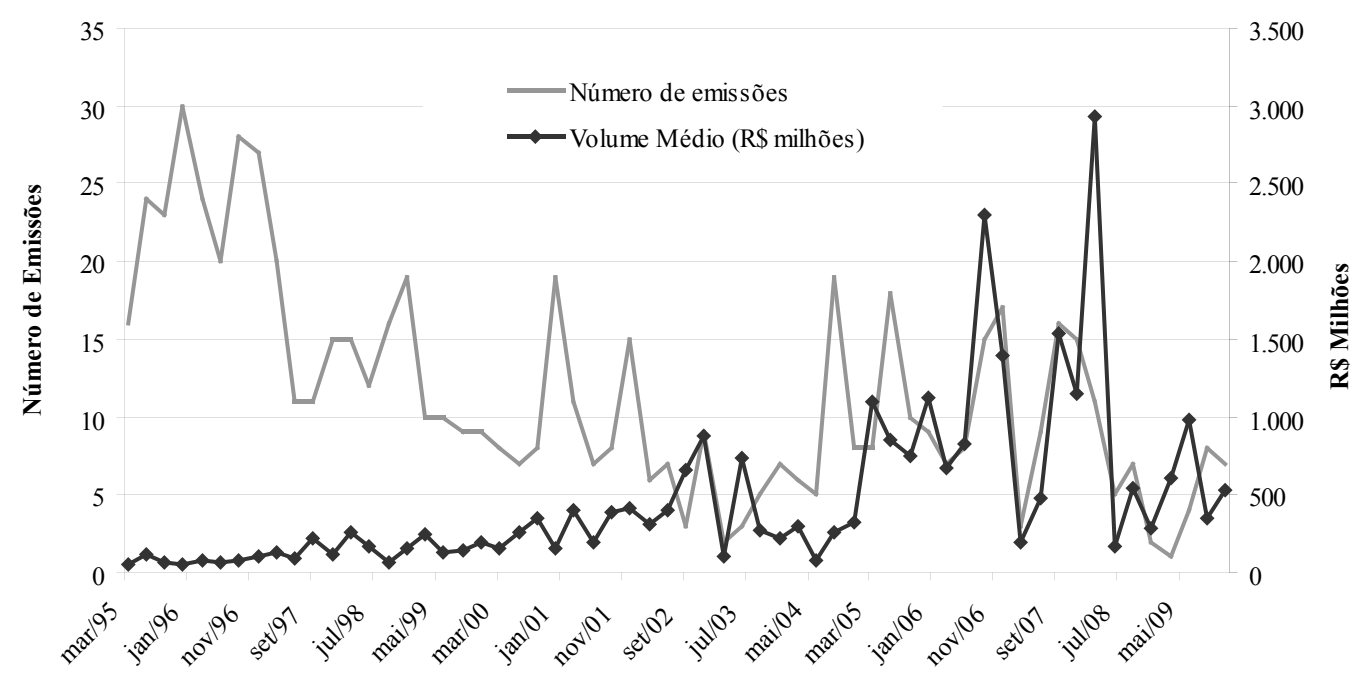

Fonte: elaborado pelos autores com dados da CVM.

Vale destacar que os títulos de dívida são elementos fundamentais para o direcionamento de recursos para o financiamento do setor produtivo de uma nação. Conforme Hanif e Jafri (2008) defendem, em um ambiente de mercado financeiro (e de capitais) desenvolvido, o nível de inovação dos produtos financeiros canaliza fundos de forma mais eficientes aos usuários mais 
eficientes. No entanto, imperfeições no mercado financeiro reduzem a habilidade de canalização eficiente de recursos entre poupadores e captadores impactando negativamente na produtividade e no crescimento econômico. Assim, níveis mais altos de desenvolvimento financeiro impactam nas vantagens competitivas da indústria de um país uma vez que alocações eficientes de recursos direcionam esses recursos para setores e empreendedores mais qualificados e que apresentam maiores chances de sucesso por implementar maiores processos inovativos.

Nesse sentido, observando-se a alocação setorial e destinação dos recursos captados pelas debêntures, verifica-se que a maior parte dos recursos captados, especialmente as grandes emissões ocorridas em 2005 e 2006, foi derivada de captações por empresas de arrendamento mercantil (leasing), que representaram o montante de 63,4\% de todas as captações ocorridas entre 1995 e 2009 . No limite, essas captações também tiveram característica de intermediação financeira, isso porque os recursos captados serviam como funding de entidades financeiras para operações financeiras de arrendamento.

As empresas de administração e participações foram, na sequencia, as que mais captaram, representando 9,3\% do total captado; em seguida, estão empresas de energia elétrica com $8,2 \%$ e empresas de telecomunicações com 3,5\%. O volume total captado e o percentual sobre o total estão apresentados na Tabela 1.

Tabela 1 - Captação total por debêntures entre 1995 e 2009 por setor de atividade do emissor

Painel A - Captação por Setor de Atividade

\begin{tabular}{l|c|c}
\hline \multicolumn{1}{c|}{ Setor } & Volume (em R\$ bilhões) & $\begin{array}{c}\text { Participação } \\
\text { Percentual }\end{array}$ \\
\hline Arrendamento Mercantil & 271,4 & $63,4 \%$ \\
\hline Empresa de Adm. e Participações & 39,9 & $9,3 \%$ \\
\hline Energia Elétrica & 35,0 & $8,2 \%$ \\
\hline Telecomunicações & 15,0 & $3,5 \%$ \\
\hline Construção Civil, Material de Constr. e Decoração & 12,6 & $2,9 \%$ \\
\hline Metalurgia e Siderurgia & 9,3 & $2,2 \%$ \\
\hline Serviços de Transporte e Logística & 6,3 & $1,5 \%$ \\
\hline Extração Mineral & 5,5 & $1,3 \%$ \\
\hline Petróleo e Gás & 4,9 & $1,1 \%$ \\
\hline Petroquímicos e Borracha & 4,0 & $0,9 \%$ \\
\hline Saneamento e Serviços de Água e Gás & 3,8 & $0,9 \%$ \\
\hline Outros & 20,6 & $4,8 \%$ \\
\hline Total Geral de Recursos Captados & $\mathbf{4 2 8 , 2}$ & $\mathbf{1 0 0 , 0 \%}$ \\
\hline
\end{tabular}

Painel B - Destinação dos Recursos Captados

\begin{tabular}{l|c|c}
\hline \multicolumn{1}{c|}{ Destinação } & Volume (em R\$ bilhões) & $\begin{array}{c}\text { Participação } \\
\text { Percentual }\end{array}$ \\
\hline Aquisição de Bens para Arrendamento & 140,8 & $32,9 \%$ \\
\hline Capital de Giro & 117,6 & $27,5 \%$ \\
\hline Alongamento do Perfil de Endividamento & 58,3 & $13,6 \%$ \\
\hline Investimento ou Aquisição de Participações Societárias & 36,1 & $8,4 \%$ \\
\hline Investimento em Imobilizado & 23,1 & $5,4 \%$ \\
\hline Redução de Passivo & 19,7 & $4,6 \%$ \\
\hline Recompra ou Resgate de Debêntures de Emissão Anterior & 9,4 & $2,2 \%$ \\
\hline Implantação de Projeto & 5,9 & $1,4 \%$ \\
\hline Outros & 17,3 & $4,0 \%$ \\
\hline \multicolumn{1}{c|}{ Total Geral de Recursos Captados } & $\mathbf{4 2 8 , 2}$ & $\mathbf{1 0 0 , 0 \%}$ \\
\hline
\end{tabular}

Fonte: Elaborado pelos autores com dados do SND.

Mesmo apresentando forte crescimento nos últimos anos, o mercado brasileiro de 
debêntures ainda é pequeno quando comparado aos mercados desenvolvidos e outras economias emergentes. Um dos principais fatores para que o mercado não esteja suficientemente desenvolvido é a falta de liquidez no mercado secundário. A baixa liquidez do mercado e o pequeno número de negociações restringem significativamente esse mercado. Em relação a isso, algumas medidas, como padronização de emissões e campanha de divulgação, foram tomadas pela BM\&FBOVESPA, ANBIMA e CETIP para tentar estimular e assegurar o mínimo de liquidez para o mercado secundário de debêntures, e o resultado foi um crescente, porém insuficiente, aumento no volume negociado.

O Gráfico 4 evidencia o aumento no volume trimestral de negociação no mercado secundário, sendo que grande parte desse aumento ocorreu, principalmente, a partir de 2007 . O volume trimestral negociado antes da crise de crédito vivenciada ao final de 2008 chegou a ser de aproximadamente R $\$ 28$ bilhões, sendo que esse volume caiu drasticamente.

Gráfico 4 - Volume trimestral de debêntures negociadas entre 1997 e 2009 em milhões Reais

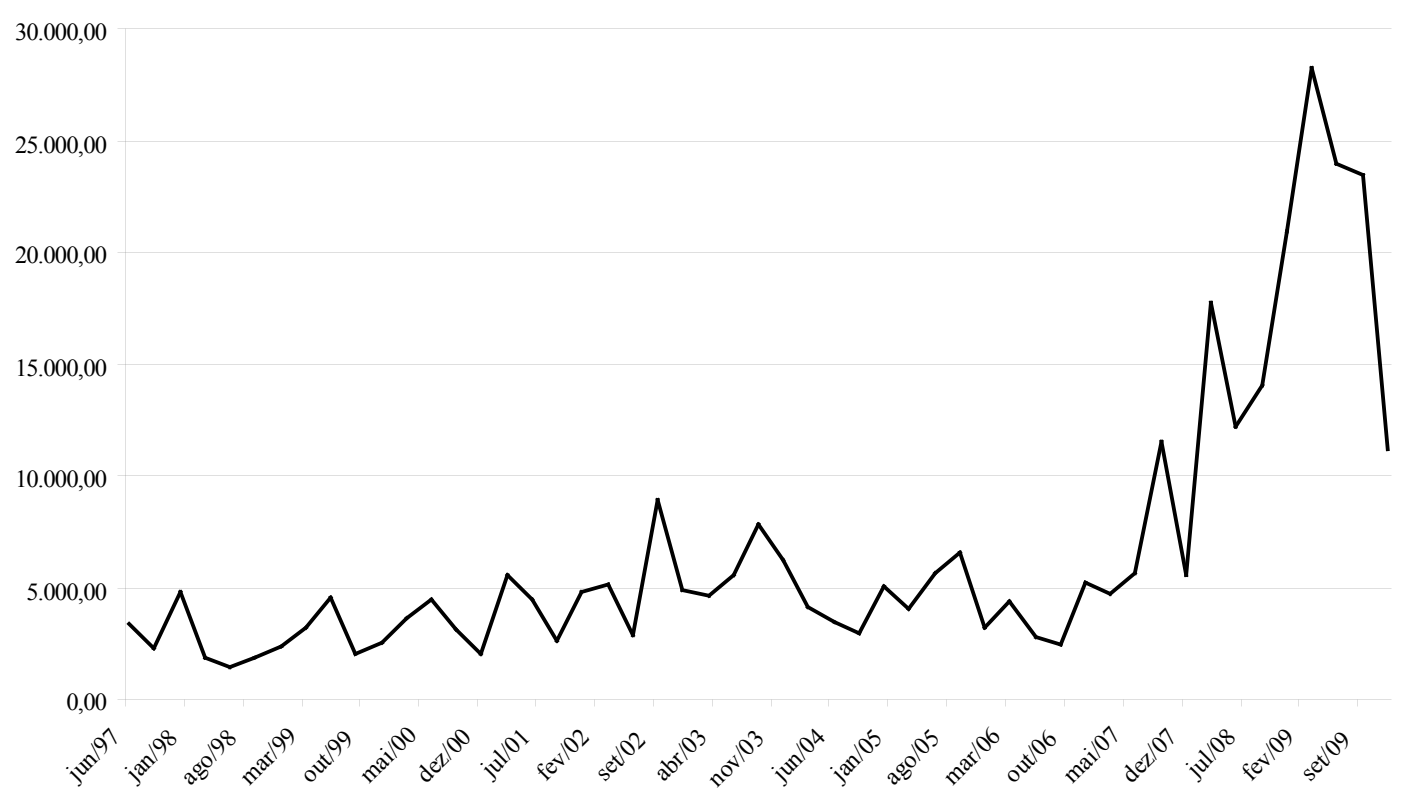

Fonte: elaborado pelos autores com dados do CVM.

Mesmo com as constantes iniciativas por parte das entidades de mercado como ANBIMA, CETIP e BM\&FBOVESPA de incentivar o mercado primário e secundário de renda fixa, Pimentel et al (2008) ainda identificam os seguintes obstáculos para um maior desenvolvimento do mercado doméstico de debêntures: (1) sistemas contábil e de auditoria confiáveis; (2) sistema jurídico eficiente na resolução de casos de falências; (3) mercado secundário de títulos livres de risco; (4) mercado secundário abrangente em termos de investidores e eficiência na liquidação das operações; (5) eficiência na previsão de insolvência de empresas e ratings financeiros e operacionais; (6) cultura de investimentos no mercado de capitais; (7) taxa de juros atrativas para emissão de títulos corporativos em detrimento de títulos do governo; e (8) menores custos operacionais na emissão de debêntures.

Apesar de não afetar diretamente as captações empresariais, o incentivo ao mercado secundário de títulos de dívida é fundamental do ponto de vista estratégico da competição comercial de uma nação. Beck (2002), por exemplo, verifica haver uma íntima relação entre países com sistemas financeiros líquidos e bem desenvolvidos e vantagens competitivas da indústria de manufatura de produtos em relação a países com baixo nível de desenvolvimento financeiro. 
Outro ponto fundamental é em relação ao alargamento dos prazos médios das captações. Em geral, as debêntures possuem prazos médios de cinco a sete anos, gerando um diferencial para os agentes tomadores; já o crédito bancário com recursos livres apresenta prazo médio inferior a um ano. De 2005 a 2008, as novas operações com debêntures tiveram prazos médios acima de sete anos. A partir de 2008, houve queda, passando para cinco anos, fruto da crise financeira internacional que limitou o crédito às empresas e reduziu os prazos das operações.

\section{APRESENTAÇÃO DOS DADOS E METODOLOGIA}

\subsection{Dados e procedimentos metodológicos}

O objetivo do presente estudo é de (1) descrever a evolução recente do mercado de debêntures, (2) analisar a relação temporal entre o mercado de debêntures e o crescimento econômico brasileiro e (3) comparar a relação temporal das debêntures com as operações de crédito bancário como instrumento complementar e concorrente no financiamento produtivo brasileiro.

Considerando que não existe uma aceitação generalizada sobre direção da causalidade entre o mercado de capitais e o crescimento econômico, este artigo testa a relação temporal entre o mercado de debêntures e o crescimento econômico brasileiro primeiramente tentando verificar a existência de relação de longo prazo por meio de análise de cointegração de séries e, após verificada a cointegração, analisa-se a direção da causalidade (causação).

A análise temporal contempla observações trimestrais entre o último trimestre de 1994 e o terceiro trimestre de 2009. Como proxy para o crescimento econômico, são utilizados os valores da formação bruta de capital (FBC) e o produto interno bruto (PIB). Como medidas dos mercados de debêntures e de crédito, são utilizados saldos em estoque e novas emissões/ concessões, conforme descritos a seguir.

A formação bruta de capital (FBC) compreende a formação bruta de capital fixo (FBCF) mais as variações de estoques, sendo que a formação bruta de capital fixo (FBCF) é o valor total dos investimentos brutos em capital fixo realizados pelas empresas públicas e privadas em um determinado período. Equivale ao aumento bruto da capacidade produtiva do país, indicando, portanto, se a capacidade de produção do país está crescendo. Este artigo utiliza-se, prioritariamente, a formação bruta de capital (que inclui variações nos estoques), pois, como pode ser verificado na Tabela 1, parte significante das captações ocorre para financiar o capital de giro das empresas. Adicionalmente, foram coletadas e analisadas as séries da formação bruta de capital fixo (FBCF) para análises complementares e aumento da robustez dos achados.

$\mathrm{O}$ produto interno bruto (PIB) utilizado neste artigo considera valores trimestrais apurados pelo IBGE e divulgados pelo Ipea-Data. São utilizadas duas medidas, o PIB a valor de mercado (PIB_MER) e o PIB a preços básicos (PIB_BAS). Este último diferencia-se do primeiro pela exclusão dos impostos sobre produtos.

O estoque de debêntures (DEBE) e o estoque de crédito bancário (CRED) são utilizados como forma de monitorar o volume do financiamento direcionado ao setor produtivo. Tais dados foram obtidos, respectivamente, do Sistema Nacional de Debêntures da ANBIMA e do Banco Central do Brasil. Adicionalmente, foram utilizadas medidas das emissões primárias trimestrais de debêntures (PRIM_DEB) e emissões trimestrais de debêntures exceto os títulos emitidos 
por empresas de leasing (PRIM_DEBEXLES). As informações sobre emissão primária foram obtidas junto à Comissão de Valores Mobiliários (CVM).

Para testar a relação temporal entre as variáveis são utilizados testes econométricos para avaliar a estacionariedade das séries, a cointegração entre as proxies de crescimento econômico e financiamento por debêntures e crédito bancário.

Segundo Brooks (2008), modelos de séries temporais geralmente são não teoréticos, implicando que sua construção e uso não são baseados em algum modelo teórico subjacente sobre o comportamento da variável. Ao invés disso, modelos de séries temporais são uma tentativa de capturar empiricamente características relevantes do fenômeno observado a fim de se gerar uma série de modelos estruturais.

Entretanto, dois pontos surgem no processo de análise do relacionamento temporal entre duas variáveis: o primeiro trata-se da possibilidade de analisar os dados em seus valores tal como eles são, ou seja, ao nível; e o segundo trata-se da possibilidade em analisar o impacto temporal da variação de uma variável em relação à outra, ou seja, dada uma variação em $x$, qual é o impacto em $y$.

O primeiro ponto consiste em uma análise de co-movimento entre séries, que, no entanto, não necessariamente avalia a "causalidade" entre as variáveis, ou seja, podem existir variáveis que possuem consistentemente correlação temporal semelhante. Por outro lado, no segundo ponto, avalia-se se, de fato, uma variação em uma variável $x$ antecipa/causa uma variação em uma variável $y$ em momentos futuros. Este artigo testa os dois elementos.

Para estudar o relacionamento temporal entre variáveis, a primeira medida é verificar se as variáveis podem ser consideradas estacionárias. A condição de estacionariedade é relevante para determinar os tratamentos adequados na análise temporal, bem como evitar problemas com relações espúrias. Sobre isso, Gujarati (2004, p.730) diz que "regressões envolvendo dados de série temporal incluem a possibilidade de se obter resultados espúrios ou duvidosos, ou seja, superficialmente, os resultados parecem bons, mas, depois de investigações adicionais, eles parecem suspeitos".

Para as variáveis não estacionárias, testa-se a hipótese de haver cointegração entre as variáveis, ou seja, se existe uma relação confiável de longo prazo. Em seguida, havendo relação de longo prazo, testa-se causalidade de Granger entre as variáveis em estudo.

\section{DESCRIÇÃO E ANÁLISE DOS RESULTADOS}

\section{1 $\quad$ Estatística descritiva}

Os dados coletados sobre operações de crédito, operações com debêntures e medidas de crescimento econômico foram analisados em sua forma original (R $\$$ milhões) e com transformação logarítmica das séries. Como se esperava, as conclusões obtidas a seguir não diferiram significativamente entre a variável "bruta" e a variável transformada (todas as divergências nos resultados são explicitadas adiante).

Este artigo apresenta apenas os resultados com a variável bruta; os resultados dos testes com a variável transformada estão à disposição mediante solicitação. A Tabela 2 apresenta as estatísticas descritivas para as variáveis. 
Tabela 2 - Estatísticas descritivas

\begin{tabular}{c|c|c|c|c|c|c|c|c}
\hline & DEBE & CRED & FBC & FBCF & PIB_BAS & PIB_MER & $\begin{array}{c}\text { PRIM_ } \\
\text { DEB }\end{array}$ & $\begin{array}{c}\text { PRIM_ DEBEXLES } \\
\text { DEBE }\end{array}$ \\
\hline Média & $71,943.2$ & $205,751.9$ & $71,858.3$ & $69,477.0$ & $355,900.9$ & $412,432.7$ & $5,210.4$ & $2,713.0$ \\
\hline Mediana & $39,566.3$ & $172,334.5$ & $59,981.9$ & $58,001.7$ & $310,235.6$ & $358,512.5$ & $2,462.0$ & $1,984.7$ \\
\hline Máximo & $270,718.0$ & $443,706.0$ & $164,832.8$ & $156,585.2$ & $687,134.5$ & $797,019.8$ & $34,519.1$ & $11,537.5$ \\
\hline Mínimo & $10,036.5$ & $103,090.0$ & $24,624.1$ & $29,196.6$ & $120,370.8$ & $135,371.2$ & 218.9 & 68.9 \\
\hline Desvio Padrão & $79,024.3$ & $87,954.3$ & $36,624.8$ & $34,063.3$ & $164,328.0$ & $193,650.7$ & $7,332.5$ & $2,076.0$ \\
\hline Observações & 60 & 60 & 60 & 60 & 60 & 60 & 59 & 59 \\
\hline Jarque-Bera & 21.437 & 28.214 & 6.839 & 7.513 & 5.225 & 5.235 & 174.761 & 81.213 \\
\hline Probabilidade & 0.000 & 0.000 & 0.033 & 0.023 & 0.073 & 0.073 & 0.000 & 0.000 \\
\hline
\end{tabular}

Dentre outros aspectos, é possível verificar que apenas as variáveis que servem como proxy do crescimento econômico (formação bruta de capital e produto interno bruto) podem ser consideradas como distribuição normal ao nível de significância de $1 \%$. O número de observações é de 60 períodos sendo as emissões primárias com 59 observações.

\section{$5.2 \quad$ Testes de estacionariedade}

Uma série estacionária pode ser definida como uma série que contém média, variância e autocovariância constantes para cada defasagem determinada. Para testar as condições de estacionariedade das variáveis, utiliza-se o teste de Dickey-Fuller Aumentado (ADF) de raiz unitária. O teste é aplicado nas variáveis em seu estado natural e em suas variações (primeira diferença) para cada empresa. De acordo com Brooks (2008), o teste de ADF consiste em identificar alguma raiz unitária que pode ser estimada conforme a seguinte equação:

$$
\Delta y_{t}=\mathrm{y} y_{t-1}+\sum_{i=1}^{p} \mathrm{a}_{i} \Delta y_{t-i}+u_{t}
$$

onde $u_{t}$ é um termo de erro que segue um processo de ruído branco puro, $p$ é o número de defasagens da variável dependente e $\Delta y_{t-1}=\left(Y_{t-1}-Y_{t-2}\right), \Delta y_{t-2}=\left(Y_{t-2}-Y_{t-3}\right)$ $\mathrm{e}$, assim, sucessivamente. $\mathrm{O}$ número de defasagens das diferenças é geralmente determinado empiricamente. $\mathrm{O}$ teste $\mathrm{ADF}$ avalia a hipótese nula de não estacionariedade no nível, verificando quando $\psi=0$.

O teste ADF foi conduzido para cada variável considerando a inclusão de intercepto e tendência linear como variáveis exógenas e com seleção automática de defasagem. Foram testadas as variáveis no nível e na primeira diferença. A primeira diferença representa a variação nominal simples de um período para o outro, ou seja, trata-se do valor em $t$ menos $t-1$. 
A primeira diferença indicará se uma variação ocorrida na atividade econômica influencia a emissão de debêntures ao longo do tempo. Em outras palavras, será possível verificar se existe causalidade entre as mudanças (choques) de uma variável na outra.

Tabela 3 - Teste de raiz unitária de Dickey-Fuller Aumentado (ADF)

\begin{tabular}{c|c|c|c}
\hline \multicolumn{4}{c}{ Variáveis no Nível } \\
\hline Series & Stat. t & Prob. & Obs \\
\hline DEBE & 0,800 & 1,000 & 59 \\
\hline CRED & $-0,151$ & 0,993 & 59 \\
\hline FBC & $-3,095$ & 0,118 & 55 \\
\hline FBCF & $-1,415$ & 0,846 & 57 \\
\hline PIB_BAS & $-1,836$ & 0,674 & 55 \\
\hline PIB_MER & $-2,103$ & 0,532 & 55 \\
\hline PRIM_DEB & $-5,565$ & 0,000 & 58 \\
\hline PRIM_DEBEXLES & $-7,812$ & 0,000 & 58 \\
\hline
\end{tabular}

\begin{tabular}{c|c|c|c}
\hline \multicolumn{4}{c}{ Primeira diferenciação (variação) } \\
\hline Series & Stat. t & Prob. & Obs \\
\hline VAR_DEBE & $-5,9321$ & 0,000 & 58 \\
\hline VAR_CRED & $-7,0905$ & 0,000 & 58 \\
\hline VAR_FBC & $-4,2582$ & 0,007 & 55 \\
\hline VAR_FBCF & $-8,8507$ & 0,000 & 57 \\
\hline VAR_PIB_BAS & $-5,5422$ & 0,000 & 55 \\
\hline VAR_PIB_MER & $-5,8007$ & 0,000 & 55 \\
\hline VAR_PRIM_DEB & $-6,8513$ & 0,000 & 54 \\
\hline VAR_PRIM_- & $-10,496$ & 0,000 & 56 \\
\hline DEBEXLES
\end{tabular}

A Tabela 3 mostra os resultados do teste de Dickey-Fuller Aumentado e é possível verificar que, como se tratam de variáveis que apresentam forte tendência de crescimento ao longo do tempo, todas as séries são não-estacionárias no nível, exceto as emissões primárias de debêntures (PRIM_DEB e PRIM_DEBEXLES). Isso sugere que, antes de se avaliar qualquer tipo de comportamento de causalidade entre as variáveis, é necessário analisar se existe relação de equilíbrio de longo prazo (teste de cointegração).

Em contrapartida, nos testes com as variáveis na primeira diferença (variações), todas as séries podem ser consideradas estacionárias com grande significância estatística (todas podem ser consideradas estacionárias ao nível de significância de 1\%). Assim, viabiliza-se diretamente o teste de causalidade entre as variáveis, sem necessidade de ajustes.

\subsection{Testes de cointegração}

Em muitos casos, se duas variáveis são I (1) (não-estacionárias), elas são linearmente combinadas. Assim, a combinação das duas variáveis também será I (1). De acordo com Engle e Granger (1987), se considerarmos que $w_{t}$ é um vetor de variáveis $k$ x 1, então os componentes de $w_{t}$ são integrados de ordem $(d, b)$ se:

(1) Todos os components de $w_{t}$ forem I (d), e

(2) Existe pelo menos um vetor para o coeficiente $\alpha$ sendo:

$$
\alpha^{\prime} w \sim I(d-b)
$$

Assim, um grupo de variáveis é definido como cointegrado se suas combinações lineares forem estacionárias. Muitas vezes, as séries são não estacionárias, mas se 'movem 
juntas' ao longo do tempo. Isso significa que existe alguma influência entre as séries que faz com que ambas sejam dirigidas por alguma correlação de longo prazo. Com isso, uma relação cointegrada pode ser vista como um fenômeno de equilíbrio de longo prazo, visto que é possível que variáveis cointegradas sejam desviadas de suas relações no curto prazo, porém, retornam no longo prazo.

Este artigo utiliza a técnica de Johansen $(1991 ; 1995)$ para testar e estimar os sistemas de cointegração. Existem dois testes estatísticos, a estatística do traço - $\left(\lambda_{\text {trace }}\right)$ - e a estatística de máximo autovalor - $\left(\lambda_{\max }\right)$ - , que, pela abordagem de Johansen, seguem, respectivamente, a formulação:

$$
\begin{gathered}
\lambda_{\text {trace }}(r)=-T \sum_{i=r+1}^{g} \ln \left(1-\lambda_{\mathrm{i}}\right) \\
\mathrm{e} \\
\lambda_{\max }(r, r+1)=-T \ln \left(1-\lambda_{\mathrm{r}+1}^{\wedge}\right)
\end{gathered}
$$

Onde $r$ é o número de vetores de cointegração sob a hipótese nula, $\lambda_{\mathrm{i}}^{\wedge}$ é o valor estimado para o $i$-ésimo autovalor ordenado da matriz $\Pi$ e $T$ é o número de observações na série de tempo. Intuitivamente, quanto maior é $\lambda_{\mathrm{i}}^{\wedge}$, menor será $\ln \left(1-\lambda_{\mathrm{i}}\right)$ e, com isso, mais significativo será o teste estatístico. Cada autovalor é associado a um vetor de cointegração diferente, que será o autovetor. Um autovalor significantemente diferente de zero indica o vetor de cointegração significante (BROOKS, 2008). A estatística do traço $\left(\lambda_{\text {trace }}\right)$ é comumente testada sob as hipóteses definidas como segue:

Ho - O número de vetores de cointegração é menor ou igual a $r$

$\mathrm{H}_{1}$ - Existe mais de um $r$

A estatística máximo autovalor $\left(\lambda_{\max }\right)$ conduz testes separados para cada autovalor em que a hipótese é definida como segue:

Ho - O número de vetores de cointegração é igual a $r$

$\mathrm{H}_{1}$ - O número de vetores de cointegração é maior que $r+1$.

A Tabela 4 apresenta um resumo dos resultados para o teste de Johansen para verificação de cointegração entre séries. O equilíbrio de longo prazo sugere que as variáveis podem ter suas relações desviadas no curto prazo, porém, essas relações retornam no longo prazo.

Como não há uma hipótese prévia sobre o comportamento temporal da relação, os testes foram feitos de maneira exploratória, considerando a existência ou não de tendência, sendo que as tendências linear e quadrática foram testadas. Adicionalmente, os testes foram desenvolvidos com e sem intercepto e com e sem tendência, conforme pode ser observado na Tabela 4. 
Tabela 4 - Resumo dos vetores de vointegração para o teste de Johansen

\begin{tabular}{c|c|c|c|c|c|c}
\hline & Tendência: & Nenhuma & Nenhuma & Linear & Linear & Quadrática \\
\hline \multirow{2}{*}{ DEB x FBC } & Tipo de Teste: & $\begin{array}{c}\text { Sem } \\
\text { Intercepto }\end{array}$ & $\begin{array}{c}\text { Com } \\
\text { Intercepto }\end{array}$ & $\begin{array}{c}\text { Com } \\
\text { Intercepto }\end{array}$ & $\begin{array}{c}\text { Com } \\
\text { Intercepto }\end{array}$ & Com Intercepto \\
\cline { 2 - 7 } & Tendência & $\begin{array}{c}\text { Sem } \\
\text { Tendência }\end{array}$ & $\begin{array}{c}\text { Sem } \\
\text { Tendência }\end{array}$ & $\begin{array}{c}\text { Com } \\
\text { Tendência }\end{array}$ & Com Tendência \\
\cline { 2 - 7 } & Max-Autov. & 1 & 1 & 1 & 1 & 1 \\
\hline \multirow{2}{*}{ DEBE x PIB_BAS } & Traço & 1 & 1 & 1 & 1 & 1 \\
\cline { 2 - 8 } & Max-Autov. & 1 & 1 & 0 & 0 & 0 \\
\hline \multirow{2}{*}{ CRED x FBC } & Traço & 1 & 0 & 0 & 1 & 1 \\
\cline { 2 - 8 } & Max-Autov. & 1 & 0 & 0 & 1 & 1 \\
\hline \multirow{2}{*}{ CRED x PIB_BAS } & Traço & 1 & 1 & 0 & 0 & 0 \\
\cline { 2 - 8 } & Max-Autov. & 1 & 1 & 0 & 0 & 0 \\
\hline
\end{tabular}

O número 1 indica que existe um vetor de cointegração ao nível de significância de 5\%.

É possível verificar que todas as relações, tanto para debêntures como para crédito bancário, possuem ao menos uma possibilidade de vetor de cointegração. A abordagem que apresenta vetores de cointegração em todas as relações foi o modelo sem tendência e sem intercepto. Os dois primeiros testes envolvem a variável debênture (DEB) e sua relação com FBC e PIB_BAS e os dois últimos envolvem a variável crédito bancário (CRED). A utilização do PIB_BAS não apresenta resultados de cointegração com a inclusão de tendência.

A relação de equilíbrio de longo prazo entre debêntures e formação bruta de capital mostrou-se significante para as abordagens do teste, sugerindo grande cointegração das séries. Para apresentar as estatísticas detalhadas do traço e do máximo autovalor, utiliza-se a abordagem sem intercepto e sem tendência.

Tabela 5 - Resumo dos vetores de cointegração para o teste de Johansen sem intercepto e sem tendência

\begin{tabular}{c|c|c|c|c|c}
\hline Relação & $\begin{array}{c}\text { Hipótese } \\
\text { Nula* }\end{array}$ & $\begin{array}{c}\text { Estatística do } \\
\text { Traço }\end{array}$ & Prob. & $\begin{array}{c}\text { Estatística do } \\
\text { Máximo Autovalor }\end{array}$ & Prob. \\
\hline DEB x FBC & $\mathrm{r}=0$ & 12,312 & 0,050 & 12,225 & 0,033 \\
\hline & $\mathrm{r}>1$ & 0,087 & 0,809 & 0,087 & 0,809 \\
\hline DEBE x PIB_BAS & $\mathrm{r}=0$ & 26,910 & 0,000 & 25,943 & 0,000 \\
\hline & $\mathrm{r}>1$ & 0,967 & 0,377 & 0,967 & 0,377 \\
\hline CRED x FBC & $\mathrm{r}=0$ & 15,845 & 0,012 & 12,964 & 0,025 \\
\hline CRED x PIB_BAS & $\mathrm{r}>1$ & 2,881 & 0,106 & 2,881 & 0,106 \\
\hline & $\mathrm{r}=0$ & 31,634 & 0,000 & 29,570 & 0,000 \\
\hline
\end{tabular}

* Hipótese nula de que não existe coeficiente de cointegração. Rejeição da hipótese nula ao nível de significância de $5 \%$ em todas as relações e pelas duas estatísticas (traço e máximo autovalor) 
A Tabela 5 detalha a estatística de Johansen para os testes de cointegração sem a inclusão de intercepto ou tendência. Para essa abordagem, todos os resultados mostram significância estatística ao nível de 5\%, conforme havia sido notado anteriormente nos resumos dos testes apresentados na Tabela 4.

Com isso, é possível afirmar que existe relação de equilíbrio de longo prazo entre as variáveis de estudo, sugerindo que, no longo prazo, quanto maior o crescimento econômico, maior o volume de títulos de dívida e de crédito em estoque. Recentemente, resultados similares sobre a cointegração entre sistema financeiro e crescimento econômico no mercado indiano entre 1993 e 2005 foram obtidos em Chakraborty (2010).

Além das evidências aqui presentes e os achados de Chakraborty (2010), na Índia existe uma aceitação generalizada sobre a relação de longo prazo entre o mercado de capitais e o crescimento econômico, no entanto, existe uma vasta discussão na literatura sobre a direção da causalidade entre as duas variáveis - ver Ray, Ray e Biswas (2009) e Andrezo e Lima (2007) para citações.

Nesse sentido, o próximo tópico visa estudar a direção da causalidade no mercado brasileiro considerando especificamente o mercado de debêntures e as proxies de crescimento econômico e investimento.

\subsection{Testes de causalidade de Granger}

De acordo com Gujarati (2004), apesar da análise de regressão tratar da dependência de uma variável em função de outras, isso não significa necessariamente causação. Em outras palavras, a existência de um relacionamento entre variáveis não prova causalidade ou a direção da influência. Para testar esse relacionamento, utiliza-se o teste de causalidade proposto por Granger (1969).

O conceito de causalidade de Granger baseia-se na melhoria da variância da previsão ocasionada pela utilização de uma variável exógena defasada na equação de regressão. A forma bidirecional é freqüentemente empregada e, neste caso, $x$ pode ser Granger Causa de $y$ e $y$ pode ser Granger Causa de $x$. A metodologia básica (para variáveis estacionárias) é o teste de causalidade de Granger em que há a realização de duas regressões bidirecionadas:

$$
\begin{gathered}
y_{\mathrm{t}}=\alpha_{0}+\alpha_{1} y_{t-1}+\ldots+\alpha_{1} y_{t-L}+\beta_{1} x_{t-1}+\ldots+\beta_{\mathrm{L}} x_{1-L}+\mathrm{e}_{\mathrm{t}} \\
x_{\mathrm{t}}=\alpha_{0}+\alpha_{1} x_{t-1}+\ldots+\alpha_{1} x_{t-L}+\beta_{1} y_{t-I}+\ldots+\beta_{L} y_{t-L}+u_{\mathrm{t}}
\end{gathered}
$$

para todos os possíveis pares $(x, y)$ de séries temporais para um específico grupo. A estatística $\mathrm{F}$ apresentada são estatísticas Wald que admitem a seguinte hipótese:

$$
\beta_{1}=\beta_{1}=\ldots=\beta_{1}
$$

Para toda equação. A hipótese nula é que x não Granger causa y na primeira equação e que 
y não é Granger causa de x na segunda regressão. Para variáveis não-estacionárias I(1), deve-se empregar o mesmo procedimento, mas sobre as variáveis diferenciadas em um período.

Os resultados dos testes de causalidade de Granger para as variáveis em estudo estão condensados na Tabela 6. Visto que os dados analisados são trimestrais (podendo ocorrer sazonalidade nas séries), a estimação das causalidades utilizou 1, 2, 3 e 4 defasagens. Essa abordagem de diferentes defasagens pode ajudar a entender melhor o comportamento temporal entre as variáveis em períodos (trimestres) diretamente anteriores e trimestres iguais em relação ao ano-calendário anterior. Adicionalmente, são apresentadas as causalidades de Granger no nível e a causalidade nas variáveis na primeira diferença (variação).

A fim de facilitar a apresentação dos dados, a Tabela 6 apresenta o P-valor para cada relação em ambos os sentidos, ou seja, medida de crescimento econômico (FBC e PIB) causando aumento nos instrumentos de captação (DEBE e CRED) e instrumentos de captação causando crescimento econômico. Assim, quando P-valor for menor que 1\%, 5\% e 10\% a causalidade é considerada significativa ao respectivo nível de significância. Para facilitar a visualização, as causalidades de Granger significativas estão destacadas na tabela.

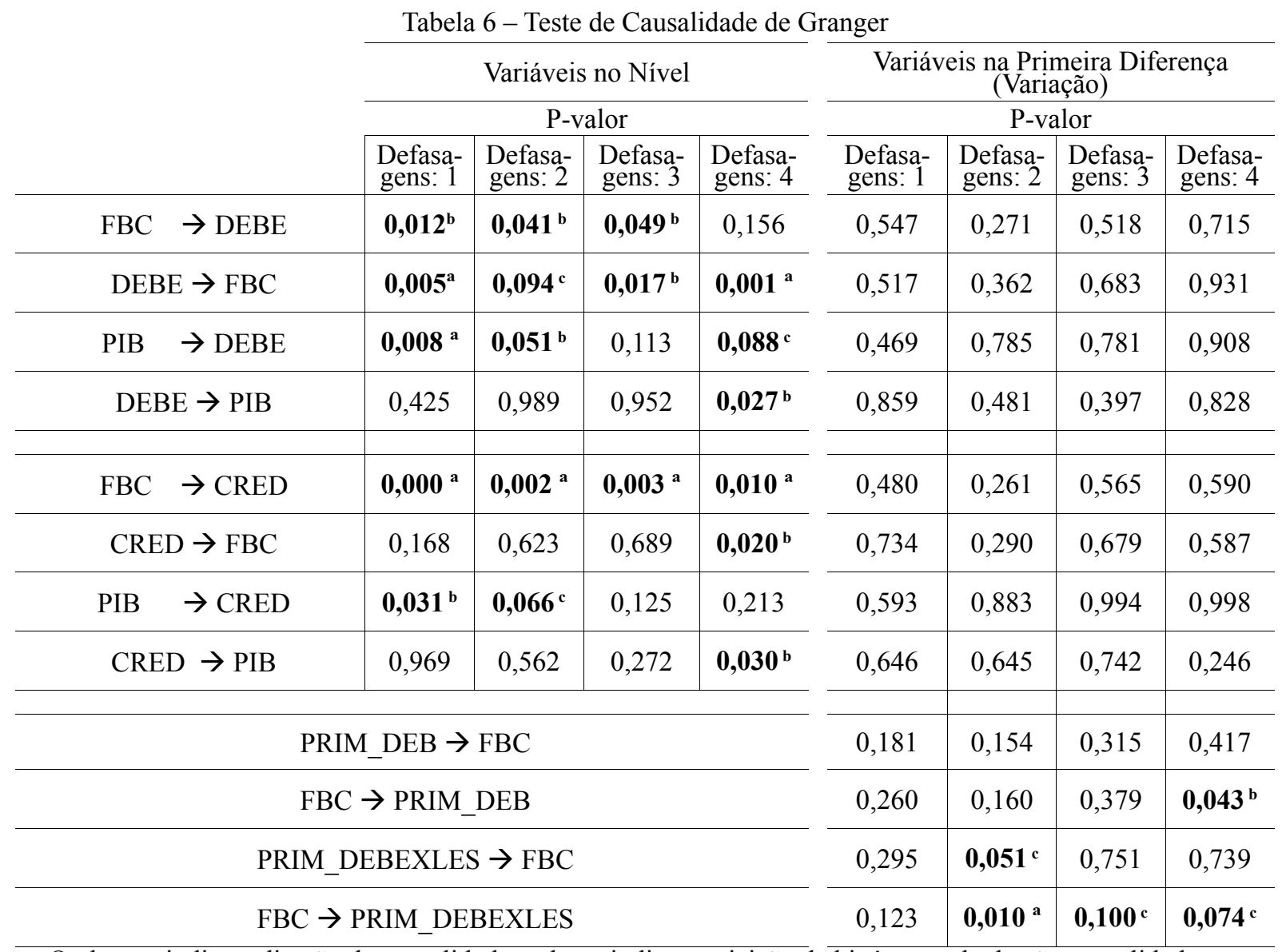

Onde, $\rightarrow$ indica a direção da causalidade. a, b e c indicam rejeição da hipótese nula de não causalidade aos níveis de significância de $1 \%, 5 \%$ e $10 \%$, respectivamente.

Como é possível verificar, o crescimento do volume em saldo das debêntures acompanha o crescimento na formação bruta de capital, sendo as duas variáveis causa Granger uma da outra. Em relação ao PIB e debêntures, verifica-se uma causalidade no sentido de que o crescimento no PIB é causa Granger das debêntures e, nesse sentido, o crescimento econômico impulsionaria 
aumento nas operações com debêntures. Em contrapartida, as debêntures só são causa Granger do PIB na quarta defasagem, havendo, portanto, uma tendência de que um aumento no saldo de debêntures estaria relacionado a um aumento (melhora) futuro no crescimento econômico (em especial quando medido pela formação bruta de capital).

Ao comparar a relação do crédito bancário às empresas, verifica-se que não existe causalidade imediata entre esse tipo de instrumento e o crescimento econômico, tanto para FBC quanto para PIB. Essa elação só é significante na quarta defasagem, sugerindo que um aumento dos volumes de crédito em carteira é causa Granger no ano social seguinte. Por outro lado, existe causalidade no sentido de que o crescimento econômico impulsiona o aumento de crédito bancário na economia.

A relação de causalidade também foi testada na colocação primária de debêntures e é possível verificar que um aumento na FBC é acompanhado por um aumento no volume captado por debêntures, especialmente quando analisadas apenas as emissões de debêntures não emitidas por empresas de leasing (DEBEEXLES). Isso corrobora a expectativa de que o crescimento econômico gera demanda adicional de recursos para empresas na economia brasileira.

Adicionalmente, os mesmos testes foram feitos com base nas variáveis com transformação logarítmica. Da mesma forma, foram utilizados os valores do PIB a valor de mercado (levando em conta impostos) e a formação bruta de capital fixo (sem considerar variações nos estoques), porém não foram identificadas mudanças significativas nas conclusões obtidas.

Análise similar comparando o mercado de capitais e as operações de crédito foi desenvolvida por Ray, Ray e Biswas (2009) que verificaram que as economias de países da região do sul da Ásia possuem diversos canais diferenciados de acumulação e distribuição de recursos. As atividades de crédito bancário eram tradicionalmente mais relevantes na região, porém, os períodos de maior desenvolvimento econômico estavam associados (maior causalidade) a períodos com maior crescimento do mercado de capitais.

Ainda que as captações por debêntures estejam limitadas a um número mais restrito de empresas, ao comparar os resultados obtidos com a análise das captações por debêntures e por crédito bancário, verifica-se que existe uma relação mais estreita entre o crescimento do mercado de debêntures e o crescimento econômico (conforme as proxies definidas neste artigo). Apesar de intrigante evidência, isso está de acordo com o apresentado por Sheng e Saito (2005) e Sant'Anna e Nascimento (2009), que sugerem que o menor custo de capital e a maior oferta de recursos direciona novas captações para financiar grandes empresas que possuem atuação nacional e internacional.

\section{CONSIDERAÇÕES FINAIS}

Este artigo teve como objetivo (1) descrever a evolução recente do mercado de debêntures, (2) analisar a relação temporal entre o mercado de debêntures e o crescimento econômico brasileiro e (3) comparar a relação temporal das debêntures com as operações de crédito bancário como instrumento complementar e concorrente no financiamento produtivo brasileiro. O período de análise foi do quarto trimestre de 1994 ao terceiro trimestre de 2009.

A descrição do mercado de capitais foi apresentada no Tópico 3 deste artigo e foi possível verificar o comportamento crescente do mercado de debêntures durante o Plano Real. Esse crescimento se deu em termos de volume, de prazo e negociação secundária dos títulos. Porém, 
o crescimento verificado ainda é insuficiente, verificou-se que a emissão de debêntures está condicionada a grandes empresas e de setores com grandes necessidades de capital como os se infraestrutura, havendo diversos desafios para o desenvolvimento consistente do mercado.

Nos testes da relação temporal entre o mercado de debêntures e o crescimento econômico, verificou-se a existência de relação significativa de longo prazo (cointegração) entre as variáveis em estudo e que, de maneira geral, o mercado de debêntures é causa-Granger do crescimento econômico especialmente com análise de quatro trimestres anteriores. Ou seja, existe indicação de que o aumento no volume de debêntures (maior captação de recursos) impulsiona o crescimento econômico, especialmente com defasagem de quatro trimestres (um ano). Em outras palavras um aumento no saldo de debêntures tende a provocar crescimento econômico após um ano.

Quando comparado às operações de crédito bancário, as captações por debêntures apresentam um relacionamento mais estreito com o crescimento econômico. Tal evidência pode ser explicada por alguns diferenciais do mercado de debêntures, dentre os quais a literatura sobre o tema destaca o menor custo de capital, maiores prazos e maior oferta de recursos que financiam, majoritariamente, investimentos de capital (investimentos de longo prazo de maturação). Com isso, grandes empresas, com atuação nacional e internacional, buscam o mercado de debêntures para captar volumes maiores otimizando sua estrutura de capital em termos de taxa e prazo.

\section{AGRADECIMENTO}

Os autores agradecem aos gestores e parceiros do CEMEC - Centro de Estudos do Mercado de Capitais pela oportunidade de desenvolvimento do estudo e aos avaliadores anônimos pelas valiosas sugestões e contribuições. Eventuais falhas remanescentes são de nossa inteira responsabilidade.

\section{REFERÊNCIAS}

AKIMOV, Alexandr; DOLLERY, Brian. Financial Sector Reforms in Indonesia and South Korea in 1980s and Early 1990s. Journal of Emerging Market Finance, v. 9(1) p.p. 25-49, 2010.

ANDERSON, Christopher W. Financial contracting under extreme uncertainty: an analysis of Brazilian corporate debentures. Journal of Financial Economics, Amsterdam, v.51, Issue 1, p.45-84, jan. 1999.

ANDREZO, Andrea F.; LIMA, Iran S.. Mercado Financeiro - Aspectos Conceituais e Históricos e Conceituais. $3^{\text {a }}$ ed. São Paulo: Atlas, 2007.

BECK, Thorsten, 'Financial Development and International Trade: Is There a Link? Journal of International Economics, 57(1). p.p. 107-131, 2002.

BROOKS, Chris, Introductory Econometrics for Finance. $2^{\text {nd }}$ ed. Cambridge University Press, UK, 2008.

CHAKRABORTY, Indrani. Financial Development and Economic Growth in India: An Analysis 
of the Post-reform Period. South Asia Economic Journal, v. 11 (2), p.p. 287-308, 2010.

COMISSÃO DE VALORES MOBILIÁRIOS - CVM. <http://www.cvm.gov.br> Acesso em jan. 2010.

ENGLE, R. F.; GRANGER, C. W. J. Cointegration and error correction: representation, estimation and testing. Econometrica, Chicago, v. 55, n. 2, p. 251-76, Mar. 1987.

GRANGER, C.W.J. "Investigating causal relation by econometric and cross-sectional method", Econometrica 37: p.p. 424-438. 1969

GUJARATI, D.N., Econometria Básica. 3.ed., São Paulo: Markon Books, 2004

HANIF, Muhammad N.; JAFRI, Sabina K., Financial Development and Textile Sector Competitiveness: A Case Study of Pakistan. South Asia Economic Journal 9(1) p.p.141-158, 2008.

JOHANSEN, Soren. Estimation and hypothesis testing of cointegration vectors in gaussian vector autoregressive models. Econometrica. v. 59 (6), p.p. 1551-1580, 1991.

JOHANSEN, Soren. Likelihood-based inference in cointegrated vector autoregressive models. Oxford: Oxford University Press, 1995.

KING, Robert G.; LEVINE, Ross. Finance and Growth: Schumpeter Might be Right. The Quarterly Journal of Economics, v. 108 (3), pp. 717-737, Aug., 1993.

NASCIMENTO, Marcelo L. Financiamento: Importância para o Crescimento Econômico, Condicionantes e Análise do Caso Brasileiro. Dissertação (Mestrado em Economia) - Faculdade de Economia, Administração e Contabilidade da Universidade de São Paulo. São Paulo, 2004.

PIMENTEL, Renê C.; LIMA, Iran S.; BORINELLI, Márcio L.; LIMA, Gerlando A.S.F. Financiamento empresarial brasileiro no mercado de dívida de longo prazo. Revista Enfoque Reflexão Contábil. v. 27, n. 1, jan./abr., 2008.

RAY, H., RAY, M.K., BISWAS, J. Bank, Market and Economic Growth : Empirical Evidence from South Asia. South Asia Economic Journal 10 (2), p.p. 403-428, 2009.

SANT'ANNA, André A.; NASCIMENTO, Marcelo M. Mercado de debêntures inicia movimento de recuperação. Visão do Desenvolvimento. Banco Nacional de Desenvolvimento Econômico e Social, ${ }^{\circ}$ 70, out. 2009.

SANVINCENTE, Antonio Z.. A Evolução Recente do Mercado Primário de Debêntures. Revista da CVM. São Paulo: 2001.

SCHUMPETER, J.A. Theory of Economic Development. Cambridge, MA: Harvard University Press, 1934.

SHENG, Hsia H.; SAITO, Richard. Determinantes de spread das debêntures no mercado brasileiro Revista de Administração, São Paulo, v.40, n.2, p.193-205, abr./mai.jun. 2005

WITT, Ulrich. How evolutionary is Schumpeter's theory of economic development? Industry and Innovation, v. 9, n. 1/2, p.p. 7-22, April/August, 2002. 


\section{ENDEREÇO DOS AUTORES:}

\section{Renê Coppe Pimentel}

FIPECAFI - Fundação Instituto de Pesq. Contábeis, Atuariais e Financeiras.

Rua Maestro Cardim, 1170 Bela Vista

São Paulo, SP - Brasil

01323-001

\section{Edna Ferreira Peres}

Universidade de São Paulo, Faculdade de Economia Administração e Contabilidade, Departamento de Contabilidade Atuária.

Rua Professor Luciano Gualberto, 908, Cidade Universitária.

São Paulo, SP - Brasil

05508-900

\section{Gerlando Augusto Sampaio Franco de Lima}

Universidade de São Paulo, Faculdade de Economia Administração e Contabilidade, Departamento de Contabilidade Atuária.

Rua Professor Luciano Gualberto, 908, Cidade Universitária.

São Paulo, SP - Brasil

05508-900 